\title{
IRREDUCIBLE ACUTE ANTERIOR DISLOCATION OF THE SHOULDER: INTERPOSED SCAPULARIS
}

\author{
SIMON H. BRIDLE, BARRY D. FERRIS
}

Failure to reduce an acute anterior dislocation of the shoulder is rare, and is usually due to the interposition of a structure into the joint. We report a case of failed reduction due to interposition of a ruptured subscapularis muscle.

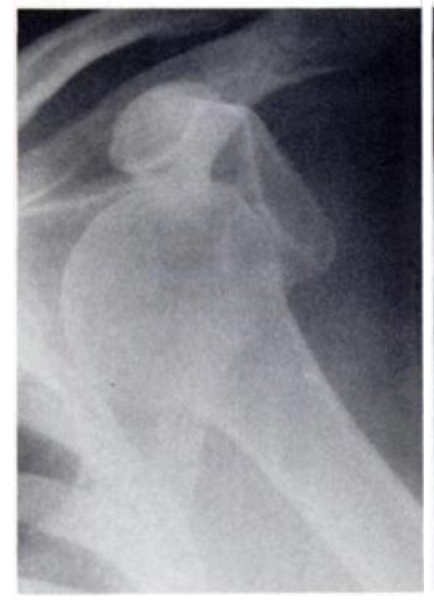

Fig. 1

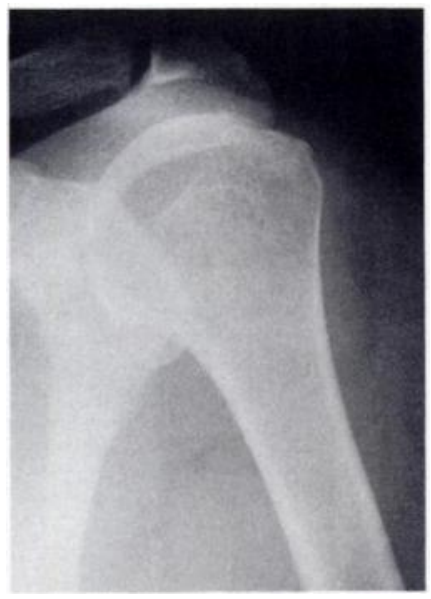

Fig. 2
Case report. A 55-year-old man fell heavily, dislocating his left shoulder. He was seen within an hour of injury, and radiographs confirmed an anterior dislocation with no associated fracture (Fig. 1). With the patient sedated, manipulative reduction by Kocher's manoeuvre was attempted. This appeared to be successful, and an anteroposterior radiograph was thought to confirm reduction, although the glenohumeral relationship was not entirely normal (Fig. 2). However, the patient immediately complained of severe pain in the shoulder and an axillary radiograph was obtained, which confirmed persistent anterior subluxation (Fig. 3).

A further manipulation was attempted under general

S. H. Bridle, FRCS, Orthopaedic Registrar

B. D. Ferris, MS, FRCS, Senior Orthopaedic Registrar

St. Helier Hospital, Wrythe Lane, Carshalton, Surrey SM5 IAA, England.

Correspondence to Mr S. H. Bridle.

(C) 1990 British Editorial Society of Bone and Joint Surgery $0301-620 X / 90 / 6 R 86 \$ 2.00$

J Bone Joint Surg [ Br] 1990; 72-B:1078-9. anaesthesia, but full reduction could not be achieved. The shoulder was therefore explored using a deltopectoral approach. The cause of the subluxation was found to be interposition into the joint of the muscle belly of subscapularis, which had been ruptured at its musculotendinous junction. Following removal of the muscle from the joint, the shoulder was reduced with ease. The muscle was repaired, and the arm immobilised. Six months later the patient had only slight restriction of movement, with no symptoms or signs of instability.

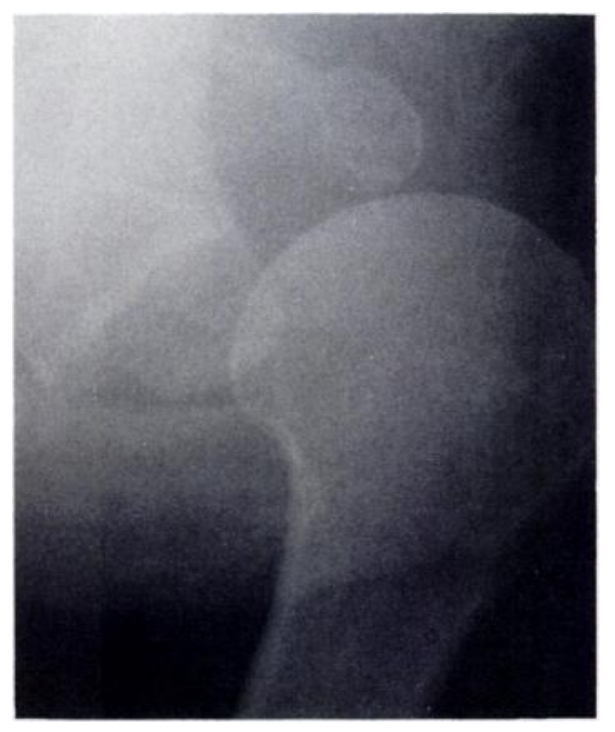

Fig. 3

Discussion. This case is unusual in two respects. First, closed reduction of the acutely dislocated shoulder is usually successful; failure may be due to interposition of the tendon of the long head of biceps (Seradge and Orme 1982), or of fragments from the greater tuberosity (Oni 1983). Also described is impaction of the Hill-Sachs defect in the humeral head against the glenoid, by bowstringing of the subscapularis tendon (Lam 1966; Kuhnen and Groves 1979). However, as far as we know, this is the first time that interposition of a ruptured subscapularis has been reported as the cause of failure.

Secondly, it is unusual to take radiographs in two planes following reduction, as abduction of the arm is 
painful, and may result in redislocation. Our case demonstrates that the shoulder may remain subluxed after apparently successful reduction; the slight loss of radiographic congruity combined with the severe pain, led to an axillary view being obtained, which demonstrated the failure. We suggest that in older patients, and in those with severe pain after an apparently successful shoulder reduction, a second radiographic view should be obtained to exclude the possibility of residual subluxation.

We thank Mr J. E. Scott, MA, FRCS, for permission to report this case.
No benefits in any form have been received or will be received from a commercial party related directly or indirectly to the subject of this article.

\section{REFERENCES}

Kuhnen W, Groves RJ. Irreducible acute anterior dislocation of the shoulder. Case report. Clin Orthop 1979; 139:167-8.

Lam SJS. Irreducible anterior dislocation of the shoulder. J Bone Joint Surg [Br] 1966; 48-B:132-3

Oni OOA. Irreducible acute anterior dislocation of the shoulder due to a loose fragment from an associated fracture of the greater tuberosity. Injury 1983; 15:138.

Seradge H, Orme G. Acute irreducible anterior dislocation of the shoulder. J Trauma 1982; 22(4):330-2.

\title{
IRREDUCIBLE ACUTE ANTERIOR DISLOCATION OF THE SHOULDER: INTERPOSED BICIPITAL TENDON
}

\author{
S. INAO, T. HIRAYAMA, Y. TAKEMITSU
}

Acute anterior dislocation of the shoulder, uncomplicated by any fracture, is usually well treated by closed manipulation. We report a case in which such a dislocation was irreducible because of the interposition of the posteriorly dislocated tendon of the long head of the biceps. We could find no previous report of this condition.

Case report. A 53-year-old man sustained an anterior dislocation of his previously normal right shoulder in a traffic accident. There was swelling and diffuse tenderness

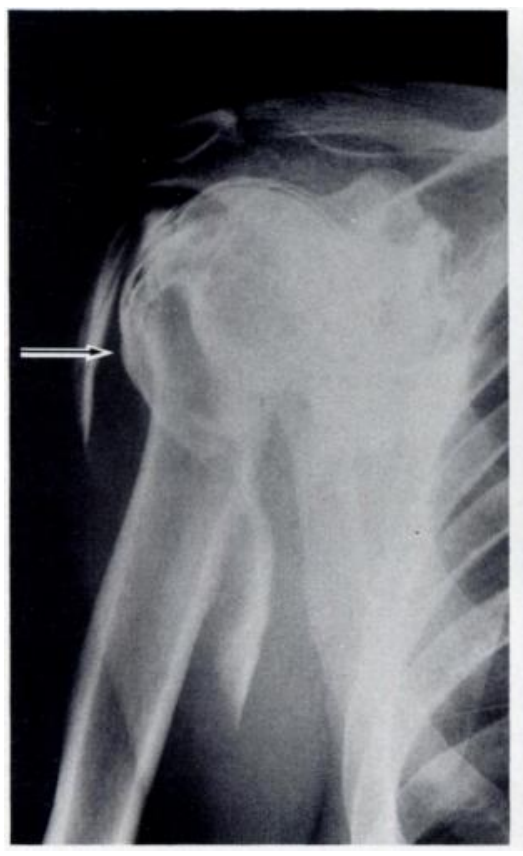

Fig. 1

S. Inao, MD, Senior Registrar

T. Hirayama, MD, Assistant Professor

Y. Takemitsu, MD, Professor and Head of Department

Department of Orthopaedic Surgery, Asahikawa Medical College, Nishikagura 4-5, 3-11, Asahikawa 078, Japan.

Correspondence to Dr S. Inao.

(C) 1990 British Editorial Society of Bone and Joint Surgery 0301-620X/90/6R01 \$2.00

J Bone Joint Surg [Br] 1990; 72-B:1079-80.

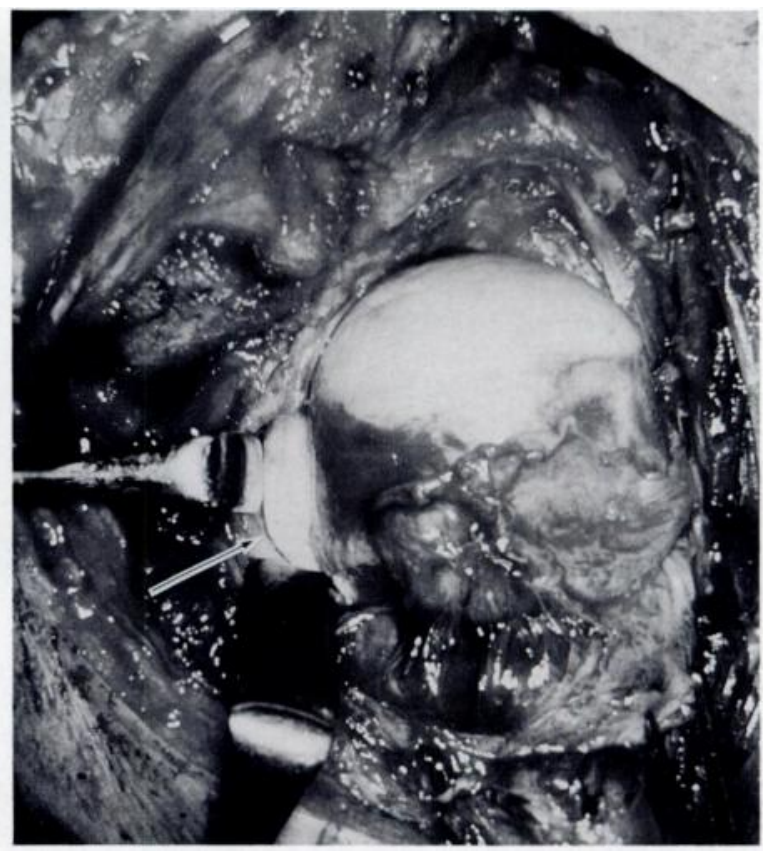

Fig. 2

but no neurovascular deficit in the arm. Radiographs confirmed an anterior dislocation with no detectable fractures. An initial attempt at closed reduction in the emergency room failed, as did further attempts under general anaesthesia.

An arthrogram then showed rupture of the rotator cuff and posterior displacement of the tendon of the long head of biceps (Fig. 1). At operation through a deltopec- 